\title{
Willingness to give amid pandemics: a contingent valuation of anticipated nongovernmental immunization programs
}

\author{
William F. Vásquez ${ }^{1}$. Jennifer M. Trudeau ${ }^{2}$
}

Received: 24 November 2020 / Accepted: 26 May 2021 / Published online: 11 June 2021

(C) The Author(s), under exclusive licence to Springer Science+Business Media, LLC, part of Springer Nature 2021

\begin{abstract}
Given that altruism is crucial in assisting impoverished households to cope with health and economic crises, it is important to improve our understanding of how preferences and motives for giving differ during a pandemic. We implemented a web-based, contingent valuation survey to estimate Americans' willingness to give for nongovernmental immunization programs in the context of the COVID-19 pandemic. Our results indicate that the median person is willing to give a one-time donation of $\$ 26$, or at least $\$ 13$ when willingness-to-give estimates are corrected for uncertainty regarding future donations. We find that willingness to give is related to income, concern levels, vaccine usage, and sociodemographic characteristics. Our findings also shed light on purely and impurely altruistic motives underlying the willingness to fund immunization programs.
\end{abstract}

Keywords Willingness to give $\cdot$ Altruism $\cdot$ Contingent valuation $\cdot$ Vaccines $\cdot$ Pandemics

JEL Classifications C25 $\cdot$ D1 $\cdot$ D64 $\cdot$ I1 $\cdot$ L31

\section{Introduction}

Amid a pandemic, altruism can play an important role in assisting impoverished households to cope with interrelated health and economic crises. However, pandemic-related emotional and economic distress may shift motives and preferences for giving (BrañasGarza et al., 2020). Predicting altruistic behaviors amid a pandemic is difficult because there are many juxtaposing factors that influence donors' willingness and ability to give. For instance, potential income reductions, e.g. reductions in wages or hours, furloughs, or unemployment, may limit donors' capacity to give, in spite of their own prosocial beliefs. On the other hand, the severity of the pandemic may increase the perceived marginal

Jennifer M. Trudeau

trudeauj@sacredheart.edu

William F. Vásquez

wvasquez@fairfield.edu

1 Department of Economics, Fairfield University, 1073 North Benson Rd, Fairfield, CT 06611, USA

2 Department of Economics and Finance, Sacred Heart University, 5151 Park Avenue, Fairfield, CT 06825, USA 
benefit of the donors' contributions to charity. These two changes may directly affect purely altruistic and impurely altruistic motives, the latter known as the 'warm-glow effect' in which the donor derives utility from the act of donating (Andreoni, 1989, 1990). A second type of impure altruism can be observed when donors themselves derive some value directly from giving to the public good being subsidized. Immunization programs for uninsured, poor households represent an example of a public good that may be beneficial for donors as well, because those programs will reduce donors' own risk of infection from people who do not have access to the vaccine and/or will mitigate the losses from a weak economy stemming from social distancing requirements. Hence, donors could be willing to fund immunization programs if they are particularly concerned about the pandemic and meeting herd immunity levels.

Given the implications of donations, it is crucial to improve our understanding of preferences for giving in response to a pandemic. Yet, few studies have investigated individuals' motives and preferences for giving monetary donations to mitigate the effects of the COVID-19 pandemic. Among the exceptions, Campos-Mercade et al. (2021) investigated giving preferences in Sweden. As an incentive to respond to questionnaires on social preferences and health behaviors adopted during the COVID-19 pandemic, participants were told that 10 of them would be randomly selected to receive a $\$ 20$ gift card. Then, respondents were asked to declare how much of the \$20 they were willing to donate to a WHO and UNICEF's Solidarity Response Fund that would help countries expand their healthcare capacity and mitigate the negative social effects of COVID-19. Campos-Mercade et al. (2021) found that more than $20 \%$ of respondents would not donate to the proposed fund, almost $50 \%$ would donate half of the value of the gift card, and the rest would donate something in between. ${ }^{1}$ In a similar study, Abel et al. (2021) implemented online experiments to measure perceived risks of COVID-19. After a series of experiments, participants were offered a bonus of $\$ 0.50$ for completing the survey. Then, they were given the opportunity to donate a share of that bonus to the CDC Emergency Fund, and were told that those funds would be used for personal protective equipment and critical response supplies. Participants donated about $\$ 0.18$, on average. More complementary studies are needed to learn how understanding giving intentions may be capitalized on to slow down the spread of a pandemic and minimize its adverse effects.

With this study, we contribute to the thin literature on preferences for giving amid a pandemic in two ways. First, we elicit giving preferences for nongovernmental immunization campaigns, as vaccines are a critical tool for mitigating the public health crisis and limiting the associated economic fallout. While prosocial attitudes may influence individuals' decisions to donate for personal protective equipment, response supplies, and healthcare services in other countries (Abel et al., 2021; Campos-Mercade et al., 2021), giving to immunization programs for uninsured people in the same country may also be a demonstration of impure altruism (e.g. self-protection and warm-glow motives). Additionally, compared

\footnotetext{
1 Brañas-Garza et al. (2020) also investigated giving intentions at the beginning of the COVID-19 pandemic. They implemented a series of experiments on economic decisions incentivized by lottery tickets for two prizes of 100 euros. Then, participants were asked whether they would donate a fraction of the prize to a nongovernmental organization should they win a prize. When comparing their estimates with results from similar experiments implemented before the pandemic, the researchers found a significant reduction of the donation amount, particularly among older individuals. However, given that the organization's name and purpose were not specified, and that the economic experiments were unrelated to the pandemic, it is not clear whether participants responded based on their preferences for giving specifically to alleviate the pandemic.
} 
to the national CDC Emergency Fund in Abel et al. (2021) and international WHO and UNICEF's COVID-19 Solidarity Response Fund in Campos-Mercade et al. (2021), nongovernmental organizations may be perceived as underfunded and more focused on underserved communities, generating altruistic motives. Hence, the context of nongovernmental immunization campaigns is appropriate to identify different factors underlying giving preferences. While there is a body of literature that addresses the role of altruism in the choice to vaccinate (e.g. Hershey et al., 1994; Shim et al., 2012), and willingness to pay for a mandated government vaccination program through taxes, i.e. paternalistic altruism (Araña \& León, 2002), we are the first, to our knowledge, to address willingness to give in the context of voluntary donations to future vaccination programs.

Second, as an alternative to incentivized experiments, we implemented a contingent valuation (CV) survey to estimate Americans' willingness to give (WTG) for impending nongovernmental immunization programs amid the COVID-19 pandemic. While incentivized experiments allow for observing actual donation choices, they also may seem unrealistic given that individuals adopt those behaviors within a small budgetary space. It is possible that individuals would adjust their giving behaviors when considering their own budget constraint. The $\mathrm{CV}$ method allows respondents to state their giving preferences under their own circumstances. Despite criticisms due to its hypothetical nature, the CV method has proven to be suitable to elicit preferences for goods that are not yet deployed (Haab et al., 2020), which was the case of COVID-19 vaccines when we implemented our survey in May 2020. Additionally, using follow-up questions, we probe motives underlying individuals' intention to give. Our results indicate that the median American is willing to give approximately $\$ 26$ to implement nongovernmental immunization programs. Our findings also suggest that while willingness to give is primarily reported as a function of purely-altruistic motives, impurely-altruistic motives of 'warm-glow' and self-protection constitute $40 \%$ of respondents' rationales.

\section{Survey design}

We designed a web-based, contingent valuation survey with five sections to investigate individual preferences. The first section documents respondents' experiences with COVID19, identifying proximity to COVID-19 cases. The second section includes Likert-type questions to investigate risk perceptions of COVID-19, and the third section includes a CV question to elicit individuals' willingness to donate money for a nongovernmental immunization program. In the fourth section, we ask about the individual's influenza vaccination practices in the prior year because it may be a good predictor of personal views regarding vaccines. Finally, our survey gathers sociodemographic information to control for heterogeneity among respondents (e.g. sex, race, income, education). We administered the survey between May 9 and May 24, 2020, using a snowball sampling strategy to recruit respondents with initial contact made through social media advertising. ${ }^{2}$ After applying data quality controls (e.g. responses to trap questions, outliers in sociodemographic variables, and inconsistencies in household composition indicating survey inattentiveness or manipulation), our sampling procedure yielded 3,043 complete surveys.

\footnotetext{
${ }^{2}$ We used paid Facebook advertisements and included 'sharing' buttons for Linked-In and Twitter in-survey.
} 
Following best practices (Boyle, 2017; Johnston et al., 2017), we designed a CV question to elicit the respondent's willingness to donate for others to have free access to the vaccine. The $\mathrm{CV}$ method is suitable to estimate the non-use value that individuals assign to goods and services that are yet to be deployed (Haab et al., 2020). While this technique is widely used in the context of willingness to pay for vaccines (e.g. García \& Cerda, 2020; Kim et al., 2014; Liu et al., 2005) we adapt the model to evaluate WTG to public provision of vaccines. The $\mathrm{CV}$ question is framed in a dichotomous format (i.e. Yes/No) as a contribution to a non-governmental organization that would provide free access to the vaccine to people who cannot afford it. We exogenously vary the amount to donate across respondents: $\$ 25, \$ 50, \$ 100, \$ 150, \$ 200, \$ 250$, and $\$ 300$. Finally, we remind respondents about their budget constraint to imprint realism to their choice. The $\mathrm{CV}$ question presented in the survey read as follows:

For the next question, assume that there is a non-governmental organization (NGO) that intends to provide COVID-19 vaccines, at no cost, to people who do not have health insurance and cannot pay for the vaccine. Also assume that the organization is asking for sponsors to make a one-time donation of [DONATION]. Keep in mind that the money you donate to that organization will not be available for other needs at your home (e.g. food, clothes, housing, transportation, recreation). Would you donate that amount of money to the organization? (Yes/No)

We included two follow-up questions to further investigate respondents' willingness to give. First, we elicited the certainty levels of respondents regarding their answer to the $\mathrm{CV}$ question using a $0-10$ scale varying from very unsure to very sure to account for bias stemming from the hypothetical nature of the CV method (Blumenschein et al., 2008; Haab et al., 2020; Ryan et al., 2017). The second follow-up question was conditional on a positive response to the $\mathrm{CV}$ question to probe reasons why respondents would donate. As discussed in the next section, individuals make donations due to purely- and impurely-altruistic motives (Andreoni, 1990; Becker, 1974). In that followup question, we present several response options to depict those motives.

\section{Analytical framework and econometric modeling}

Andreoni's (1989, 1990) model on impure altruism provides a theoretic framework to analyze the respondents' choice to contribute to the non-governmental immunization program proposed in the contingent scenario. In that model, individuals derive utility from income $(Y)$ and from donating to a public good (i.e. immunization against COVID19) based on both altruism and self-regard. In the context of the proposed immunization campaign, the respondent may give so uninsured individuals have access to the vaccine (i.e. pure altruism), to restore the economy or reduce the risk of being infected by others (i.e. impure altruism). The respondent can also derive utility due to warm-glow motives (another form of impure altruism). To depict those motives, the donation $g_{i}$ enters the utility function $V$ in three forms: (1) by reducing income available for other goods and 
services, (2) through the public good to which the person contributed $\left(\mathrm{G}=\sum_{j \neq i} g_{j}+g_{i}\right)$, and (3) directly due to warm-glow reasons. ${ }^{3}$ Consequently, an individual will donate as long as the utility lost due to income reduction is compensated by utility gains from contributing to the public good, i.e. $V_{0}\left(Y, G_{-i}, 0\right)=V_{1}\left(Y-g_{i}, G, g_{i}\right)$ where $G_{-i}=\sum_{j \neq i} g_{j}$. A concave utility function is assumed, which implies that the marginal utility of giving decreases with the donation amount.

In our empirical modeling, we assume that the maximum donation amount that individual $i$ is willing to give $\left(g_{i}\right)$ follows a log-linear specification:

$$
\ln \left(g_{i}\right)=X_{i} \beta+e_{i}
$$

where $X$ is the vector of covariates, $\beta$ represents the coefficients to be estimated, and $e$ is the idiosyncratic error term. We implemented a dichotomous question that allows for indirectly estimating the individual willingness to donate. Although $g_{i}$ is not observed in the dichotomous format, it can be traced given that the respondent gives a positive answer only if her willingness to donate is greater than or equal to the bid presented in the contingent scenario. This implies that there is an equivalence between the probability of a positive response and the probability that the natural logarithm of $g_{i}$ is greater than or equal to the natural logarithm of the proposed bid, i.e. $\mathrm{P}(\mathrm{Yes})=\mathrm{P}\left(\ln \left(g_{i}\right) \geq \mathrm{LNBID}\right)=\mathrm{P}(X \beta+e \geq \mathrm{LNBID}$ ). Consequently, the probability that an individual will donate $(\mathrm{P})$ can be modeled using a logit specification:

$$
L N\left(\frac{P}{1-P}\right)=\alpha L N B I D+X \delta+e
$$

where $\alpha$ and $\delta$ are coefficients to be determined using a maximum likelihood estimation approach, under the assumption that the stochastic error term $e$ follows a logistic distribution. Estimated coefficients (i.e. $\hat{\delta}$ and $\hat{\alpha}$ ) can be used to compute the median WTG to nongovernmental immunization programs as: $e^{-(X \delta / \widehat{\alpha})}$, where $\bar{X}$ is a vector of the average of covariates.

Table 1 shows the variables included in vector $X$. The variable $L N B I D$ is included to depict the effect of the donation amount presented in the contingent scenario on the likelihood of giving to nongovernmental immunization programs. Consistent with our theoretic framework, we expect this effect to be negative because both the marginal utility of giving decreases with the increasing donation amounts, and utility decreases at a faster rate with each additional dollar that will not be available for own needs. Our theoretic framework also indicates that WTG is related to household income. Therefore, we included the variable INCOME to test the hypothesis that the likelihood of giving increases with household income.

We also tested several empirical hypotheses to evaluate differential replies across respondents. We included the binary indicator CONCERNED to depict differentials in WTG between those who are concerned or very concerned about COVID-19 relative to individuals who are not worried about it. Compared to the latter, concerned individuals are expected to be more likely to support immunization programs-due to the fact that it reduces the probability of continued spread of the virus, which is consistent with increasing the value of the public good (Andreoni, 1989, 1990). Additionally, we use a binary

\footnotetext{
3 Additionally, or instead of voluntary donations, the public good may be funded through a tax as in Araña and León (2002).
} 


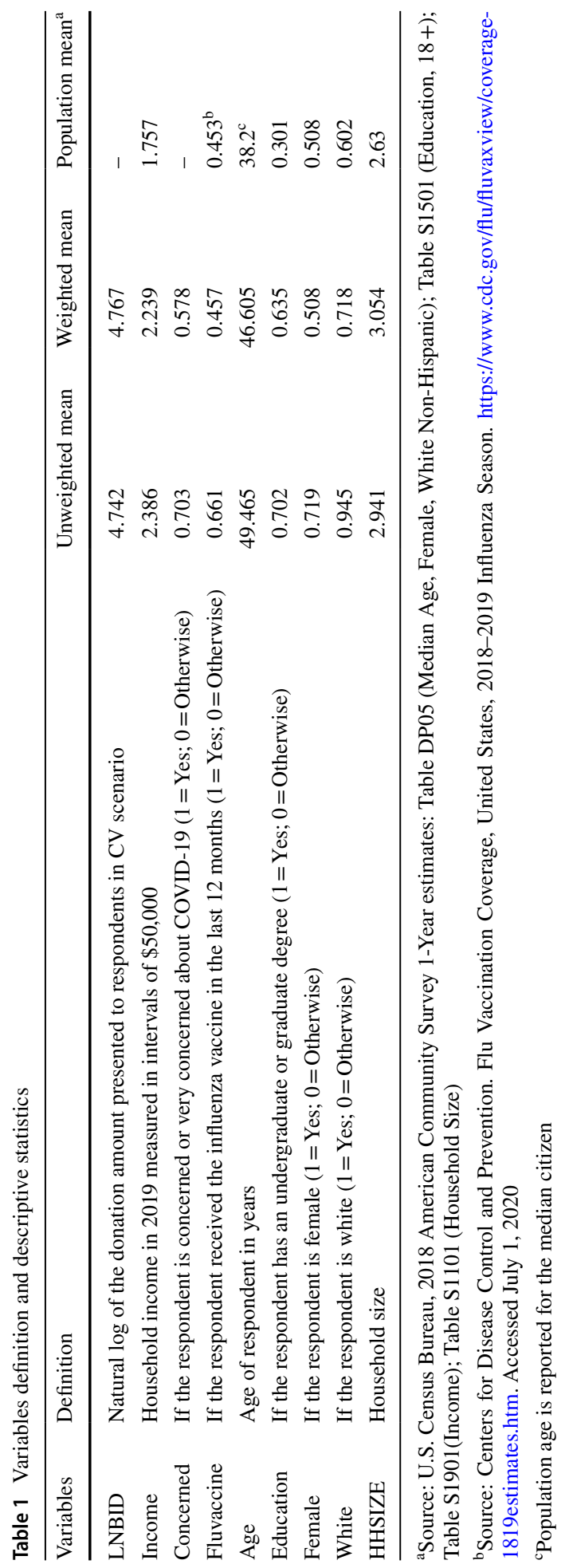


indicator to distinguish between respondents who got the influenza vaccine in the last 12 months from those who did not (FLUVACCINE). It may be a proxy for risk aversion if those who elect to receive the flu vaccine, on average, get it to reduce risk for themselves or for household members. They might have the most to gain from herd immunity resulting from efficient vaccination campaigns. On the other hand, those who took the influenza vaccine may also be more likely to get vaccinated against COVID-19 than their counterparts. In that case, they would be protected and thus would have the least to gain from herd immunity. Therefore, the effect of FLUVACCINE remains to be empirically investigated. Similarly, we do not have apriori expectations for other factors included to control for heterogeneity among respondents such as respondent's age, education, sex, race, and household size.

In our empirical strategy, we also consider that the hypothetical nature of the valuation question can lead to a bias in stated willingness to pay (Liljas \& Blumenschein, 2000). A number of studies have demonstrated that hypothetical biases are partially related to respondents' uncertainty regarding future behavior, and that it can be mitigated by recoding favorable responses as negative when certainty levels are relatively low (Blumenschein et al., 2008; Ryan et al., 2017). To address hypothetical biases, we elicited respondents' certainty levels regarding their answer to the CV question using a scale from 0 to 10 , where 0 meant completely uncertain and 10 completely certain. Certainty responses can be used to reduce the hypothetical bias and obtain more accurate willingness-to-pay estimates (Blumenschein et al., 2008; Ryan et al., 2017). Moreover, Champ et al. (2009) found that the certainty question was more effective than other methods for estimating actual WTP values. We used responses to the follow-up certainty question to recode positive responses as negative if the respondent's certainty level was below seven. Vásquez et al. (2009) and Ryan et al. (2017) followed a similar approach to mitigate hypothetical biases in WTP estimates for safe drinking water and a prepaid oral care plan, respectively.

One of the challenges to our estimation approach is the coverage bias inherent in our convenience sampling. To address this problem, we correct by weighting with an iterative proportional fitting (raking) procedure (Kolenikov, 2014). We generate weights along three dimensions: by sex-age groups (Male/Female $\times 3$ age groups: 18-34, 35-59, 60+), region (Northeast, South, Midwest, West) and race (non-Hispanic White and all others), based on the 2018 American Community Survey (Ruggles et al., 2020). While we report the results using untrimmed weights in the text that follow, all results are robust to trimming extreme outliers. Additionally, Harrison and Lesley (1996) demonstrated that convenience samples may yield accurate estimates when resulting contingent valuation models are calibrated using population means. Hence, following Harrison and Lesley (1996), Holmes et al. (2004), and Mozumder et al. (2011), we predict the median WTG using population averages (as reported in Table 1).

\section{Results}

The descriptive statistics shown in Table 1 provide a profile of the average respondent. Approximately $72 \%$ were female, and $94 \%$ identified themselves as White. The average respondent was 49 years old, lived in a household of three members, and earned between $\$ 100,00$ and $\$ 150,000$ in 2019 . Approximately $66 \%$ had received a vaccine against influenza in the previous 12 months, and more than $70 \%$ reported to be concerned or very concerned about COVID-19. This sample of respondents does not accurately reflect the adult 
Table 2 Logit models of willingness to give (marginal effects)

\begin{tabular}{|c|c|c|c|c|}
\hline Variables & Model 1 & Model 2 & Model 3 & Model 4 \\
\hline LNBID & $\begin{array}{l}-0.096 \\
(0.016)^{* * *}\end{array}$ & $\begin{array}{l}-0.096 \\
(0.016)^{* * *}\end{array}$ & $\begin{array}{l}-0.096 \\
(0.016)^{* * *}\end{array}$ & $\begin{array}{l}-0.096 \\
(0.016)^{* * *}\end{array}$ \\
\hline Income & $\begin{array}{l}0.033 \\
(0.011)^{* * *}\end{array}$ & $\begin{array}{l}0.033 \\
(0.011)^{* * *}\end{array}$ & $\begin{array}{l}0.034 \\
(0.011)^{* * *}\end{array}$ & $\begin{array}{c}0.034 \\
(0.011)^{* * * *}\end{array}$ \\
\hline Concerned & $\begin{array}{l}0.363 \\
(0.035)^{* * *}\end{array}$ & $\begin{array}{l}0.363 \\
(0.035)^{* * * *}\end{array}$ & $\begin{array}{l}0.366 \\
(0.035)^{* * *}\end{array}$ & $\begin{array}{c}0.366 \\
(0.035)^{* * *}\end{array}$ \\
\hline Fluvaccine & $\begin{array}{l}0.109 \\
(0.031)^{* * *}\end{array}$ & $\begin{array}{l}0.109 \\
(0.031)^{* * *}\end{array}$ & $\begin{array}{l}0.109 \\
(0.031)^{* * * *}\end{array}$ & $\begin{array}{c}0.108 \\
(0.031)^{* * * *}\end{array}$ \\
\hline Age & $\begin{array}{l}-0.002 \\
(0.001)^{* *}\end{array}$ & $\begin{array}{l}-0.002 \\
(0.001)^{* *}\end{array}$ & $\begin{array}{l}-0.002 \\
(0.001)^{* * * *}\end{array}$ & $\begin{array}{l}-0.003 \\
(0.001)^{* * *}\end{array}$ \\
\hline Education & $\begin{array}{c}0.062 \\
(0.032)^{*}\end{array}$ & $\begin{array}{l}0.063 \\
(0.032)^{* *}\end{array}$ & $\begin{array}{l}0.064 \\
(0.031)^{* *}\end{array}$ & $\begin{array}{c}0.064 \\
(0.031)^{* *}\end{array}$ \\
\hline Female & $\begin{array}{l}-0.065 \\
\quad(0.029)^{* *}\end{array}$ & $\begin{array}{l}-0.064 \\
\quad(0.028)^{* *}\end{array}$ & $\begin{array}{l}-0.066 \\
\quad(0.029)^{* *}\end{array}$ & $\begin{array}{l}-0.064 \\
(0.028)^{* *}\end{array}$ \\
\hline White & $\begin{array}{c}0.077 \\
(0.042)^{*}\end{array}$ & $\begin{array}{c}0.077 \\
(0.042)^{*}\end{array}$ & $\begin{array}{c}0.077 \\
(0.042)^{*}\end{array}$ & $\begin{array}{c}0.076 \\
(0.042)^{*}\end{array}$ \\
\hline HHSIZE & $\begin{array}{l}-0.019 \\
(0.009)^{* *}\end{array}$ & $\begin{array}{l}-0.019 \\
(0.009)^{* *}\end{array}$ & $\begin{array}{l}-0.020 \\
\quad(0.010)^{* *}\end{array}$ & $\begin{array}{l}-0.020 \\
(0.010)^{* *}\end{array}$ \\
\hline Regional fixed effects & No & No & Yes & Yes \\
\hline Linear time trend & No & Yes & No & Yes \\
\hline Pseudo $\mathrm{R}^{2}$ & 0.211 & 0.211 & 0.214 & 0.214 \\
\hline
\end{tabular}

Observations $=3043$. Weighted standard errors are reported in parentheses. $*, * *$ and $* * *$ imply statistical significance at $10 \%, 5 \%$ and $1 \%$ level, respectively

population of the United States, with a low representation of males and minority groups. The average age, education, and income profile are above the population average, presumably due to the selection bias of active participants on social media. Sampling weights correct for the misrepresentation of several groups, with the exception of income and education that remained above the population average. We use these sampling weights in each of our analyses of individuals' WTG and their underlying motives for giving.

\section{Willingness to give to nongovernmental immunization programs}

Table 2 shows four logit models of willingness to give to nongovernmental organizations to provide uninsured, poor families with access to the COVID-19 vaccine. The models differ from each other in terms of controls for time trends and regional WTG differentials. Model 1 , our parsimonious model, does not control for time trends or regional fixed effects. Model 2 and Model 3 incorporate controls for time trends and regional fixed effects, respectively. Finally, Model 4 controls for both time and regional effects. The results that follow are robust across all specifications.

Estimated coefficients on LNBID indicate that the likelihood of giving decreases with the size of the donation presented in the contingent scenario. This finding suggests that the marginal utility of giving diminishes with each additional dollar donated. Correspondingly, 
the marginal utility lost for not having an additional dollar for own needs increases with the size of that donation. On the other hand, estimated coefficients on income are positive and statistically significant across all model specifications, which indicates that the probability of giving increases with household income. Together, these findings lend support to the construct validity of our contingent scenario.

The results also indicate that concern levels influence the willingness to give to nongovernmental immunization programs. Estimated coefficients of CONCERNED indicate that individuals who are concerned or very concerned about COVID-19 are about 36 percentage points more likely to give than those who are not concerned. Concerned individuals may perceive nongovernmental programs as necessary to ensure universal immunization against the virus, and thus minimize their own risk of infection. Similarly, individuals who received an influenza vaccine in the last 12 months are more likely to give than those who did not receive the vaccine by about 11 percentage points. Their decision to receive the influenza vaccine is a signal of their own acceptance of the validity of vaccines, and preference towards minimizing health risks for themselves and others, especially in the context of a virus with lower mortality/morbidity. It may suggest that they have stronger preferences for widespread immunization as a key strategy to promote health.

Our findings also suggest that some personal and household characteristics influence the decision to give to nongovernmental immunization programs. For instance, the probability of giving decreases with age. This finding is consistent with prior studies that suggest that individuals show less health altruism near retirement age (Long \& Krause, 2017). It may be argued that, relative to young people, older individuals have stronger preferences for saving for retirement and thus are less likely to give. Conversely, results indicate that the likelihood of giving increases with education. Individuals with a college degree are about six percentage points more likely to give than individuals without higher education. An understanding that collective action is crucial to mitigate health and economic crises may increase with education.

We found that females are less likely to give than males by about six percentage points. This is somewhat at odds with the literature on the role of gender and giving (see reviews by Wiepking \& Bekkers, 2012; Mesch et al. 2011) and findings that women are more likely to donate to health-related charities (Andreoni et al., 2003) and disaster relief (Eckel et al., 2007). The distinctions of our study are: (1) our specific definition of the health intervention, i.e. vaccine only, which has been known to engender strong reactions from pro- and anti-vaxxers (Smith et al., 2004), (2) the uncertainty and yet, pervasiveness of the impact of the COVID-19 pandemic, and (3) our inclusion of controls for attitudes towards the virus (CONCERN) and vaccine (FLUVACCINE).

We also found race differentials in the likelihood of giving. Non-Hispanic white respondents are more likely to donate than their counterparts by almost eight percentage points. The literature, summarized in Mesch et al. (2006), indicates that observed effects by race are inconsistent across specifications, sometimes diminished by the inclusion of controls for human capital or multivariate modelling. Our results, based on a multivariate model with human capital controls, may reflect differences in beliefs towards or access to vaccines by race and ethnicity (Quinn et al., 2017), not otherwise captured by our CONCERN and FLUVACCINE controls. In the United States, non-Hispanic Blacks, Hispanics, and non-Hispanic Asian minorities typically have lower probabilities of vaccination than Whites (Almario et al., 2016; Lu et al., 2015; Marin et al., 2002). Finally, the likelihood of giving decreases with 


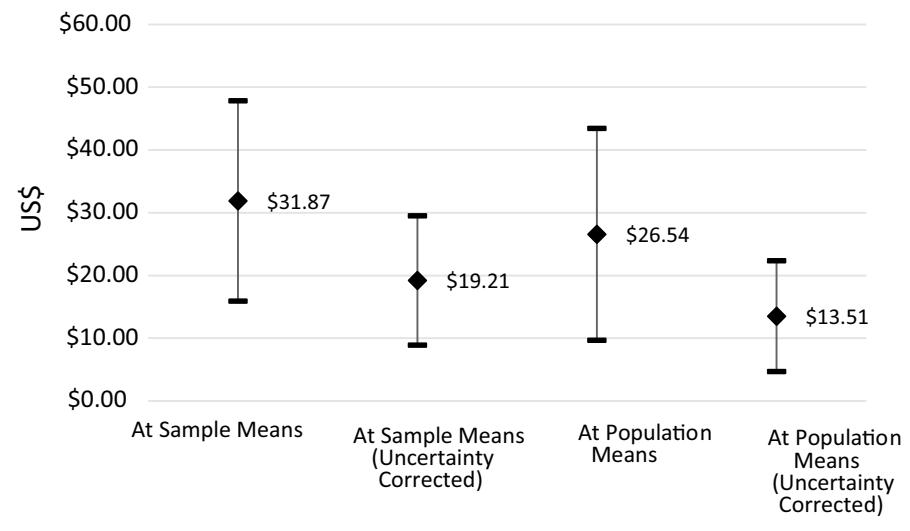

Fig. 1 Willingness-to-Give Estimates (95\% Confidence Intervals). Note: These estimates are based on Model 4. WTG estimates were corrected for uncertainty by recoding positive responses whose certainty levels were below 7 on a $1-10$ scale as negative

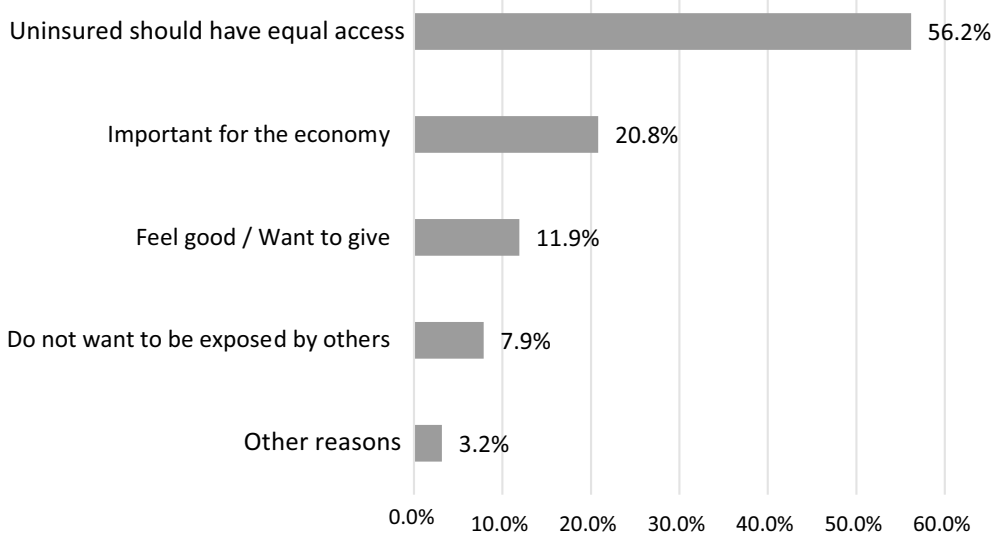

Fig. 2 Reasons for Giving Reported by Sampled Individuals. Note: Observations =1,358

household size. This result is consistent with the prediction that household expenses increase with additional household members, which leaves less money available for donations. ${ }^{4}$

Our models can be used to compute the median WTG. Given that all models yield similar estimates, we elect to report the median WTG for the least restrictive model, Model 4. Figure 1 shows confidence intervals for the median WTG. The far-left observation shows that the median individual in our sample is willing to give approximately US\$ 32 for nongovernmental COVID-19 immunization programs. In recognition of the potential hypothetical biases resulting from the contingent scenario, we compute more conservative estimates by accounting for the uncertainty of donors (Blumenschein et al., 2008). Those responses whose certainty levels were below 7 on a 1-10 scale were

\footnotetext{
${ }^{4}$ In our robustness tests, we include indicators for current employment status and access to health insurance. Corresponding coefficients were statistically insignificant across all models and did not significantly affect the coefficient estimates of other variables.
} 
Table 3 Multinomial probit model of respondent characteristics associated with giving motives (marginal effects)

\begin{tabular}{lcccc}
\hline & Equal access & Economy & Feel good & Own health \\
\hline Income & -0.021 & 0.037 & -0.008 & -0.009 \\
Concerned & $(0.019)$ & $(0.014)^{* * *}$ & $(0.016)$ & $(0.006)$ \\
& $(0.0637$ & -0.008 & -0.097 & 0.041 \\
Fluvaccine & -0.050 & $(0.074)$ & $(0.064)$ & $(0.014)^{* * *}$ \\
& $(0.060)$ & 0.065 & -0.077 & 0.062 \\
Age & -0.00007 & 0.0003 & -0.0001 & -0.00006 \\
& $(0.002)$ & $(0.001)$ & $(0.001)$ & $(0.001)$ \\
Education & 0.049 & -0.006 & -0.030 & -0.013 \\
& $(0.062)$ & $(0.057)$ & $(0.041)$ & $(0.020)$ \\
Female & 0.125 & -0.081 & -0.043 & -0.0004 \\
& $(0.051)^{* *}$ & $(0.046)^{*}$ & $(0.034)$ & $(0.015)$ \\
HHSIZE & -0.019 & 0.002 & 0.014 & 0.004 \\
& $(0.019)$ & $(0.014)$ & $(0.012)$ & $(0.005)$ \\
\hline
\end{tabular}

Observations $=1315$. Weighted standard errors are reported in parentheses. $*, * *$ and $* * *$ imply statistical significance at $10 \%, 5 \%$ and $1 \%$ level, respectively. The model controls for regional fixed effects and a linear time trend

recoded as negative, i.e. 'No, would not donate.' Based on those WTG estimates, the median person would donate about US\$ 19 to fund nongovernmental COVID-19 immunization programs.

We also predicted the median WTG at population means to address potential biases introduced by our convenience sampling strategy (Harrison \& Lesley, 1996; Holmes et al., 2004; Mozumder et al., 2011). Those WTG estimates are shown in the two right-most observations in Fig. 1. We observe lower population-based WTG estimates at \$26 without correcting for response uncertainty and $\$ 13.50$ when the correction is made. It is worth noting that population-based estimates lie within sample-based confidence intervals, and that uncertainty-corrected estimates of the median WTG lie within the (uncorrected) WTG confidence intervals. Based on these comparisons, we are confident that potential sampling bias in our estimates is minimal.

\section{Motives for giving}

We further investigate motives of those respondents who chose to give in the contingent scenario with a follow-up question. Figure 2 shows the distribution of those motives. A majority of donors would support nongovernmental organizations to provide equal access to the vaccine to people without health insurance, who otherwise could not afford it. The second most commonly reported reason to give is that universal coverage of a vaccine against COVID-19 is perceived as crucial for a prompt economic recovery. Other motives include feeling good when giving and reducing their own exposure by making sure more people are vaccinated (impure altruism). These results may reveal that although 'warm glow' has been shown to be important in experimental evaluations of donations of time 
(Brown et al., 2019) and money (Crumpler \& Grossman, 2008; Tonin \& Vlassopoulos, 2010), in the midst of a pandemic when there are limited funds available, social justice, as well as individual economic and health benefits dominate the donation reasoning.

Table 3 summarizes the marginal effects of a multinomial probit model that estimates the influence of individual characteristics associated with each motive. ${ }^{5}$ We have designated the response calling for equal access to vaccines for the uninsured as a purely- altruistic motive, calling for social justice or equity in access to vaccinations. Female respondents have an increased probability of reporting this motive, 12.5 percentage points, relative to the excluded category of males.

Of the remaining impurely altruistic motives, we split our discussion into three categories: a financial benefit from the strength of the economy, a direct health benefit from the promotion of herd immunity, and 'warm glow' motives. The donors who are most concerned about the economic ramifications of a second wave of coronavirus, ${ }^{6}$ are likely of higher income status, but are less likely female, as we saw women tended to report altruistic intentions. The effect of income on this selected motivation is consistent with the belief that individuals with higher income may perceive higher opportunity costs associated with adverse economic effects of COVID. The 'warm glow' motive of donating making respondents feel good, is negatively associated with having received a flu vaccine in the last 12 months, significant only at the $10 \%$ level. When it comes to individual health protection $^{7}$ as the primary motivator, we find that concern and flu vaccine are positive predictors. To the extent that concern and recent flu-vaccination captures people (1) with high anxiety associated with the virus, (2) those at high risk or (3) in proximity to people at risk of severe COVID cases, there is a 4.1 percentage point increase in the probability of signaling not wanting to get sick from others.

\section{Discussion and conclusions}

Using a web-based contingent valuation survey, we predicted individuals' willingness to give for nongovernmental immunization programs amid the COVID-19 pandemic, and analyzed their motives to give. At the time of survey implementation, immunization programs represented a highly anticipated public good; however, policymakers had not yet announced how COVID-19 vaccines were going to be distributed, if and when a safe and effective vaccine was produced. Hence, our study helps us understand giving preferences from the initial stages of a pandemic, in spite of the fact that ultimately the US government

\footnotetext{
5 The multinomial probit (MNP) model is suitable to estimate the probability that an individual chooses a given option among a set of $J$ options. In the context of our study, we assume that there is a latent variable depicting the intensity that individual $i$ experiences regarding each option $j$ as shown in Fig. 2, i.e. $I_{i j}$. That intensity can be represented in a linear form: $I_{i j}=Z_{i} j+u_{i j}$, where $Z$ is a vector of individual characteristics, is the vector of coefficients to be estimated, and $u$ represents the stochastic error term that follows a normal distribution. The MNP specification models the probability that the intensity of the chosen option $(k)$ is greater than the intensity of other options, i.e. $\mathrm{P}\left(I_{i k}>I_{i j}\right)$ for all $j k$. See Greene (2018) for a technical discussion of the MNP model. Note that, in our empirical estimation, we excluded respondents who reported other reasons for giving due to its low representativeness (3.2\%). In addition, relative to the specification of models in Table 2, we excluded the indicator WHITE because it did not vary for one of the options.

6 Recall, this survey was administered in the month of May 2020 at which point the first-wave was slowly declining in the United States.

7 The health benefit may include an indirect financial benefit of reductions in lost productivity in addition to the direct increase in utility due to health status.
} 


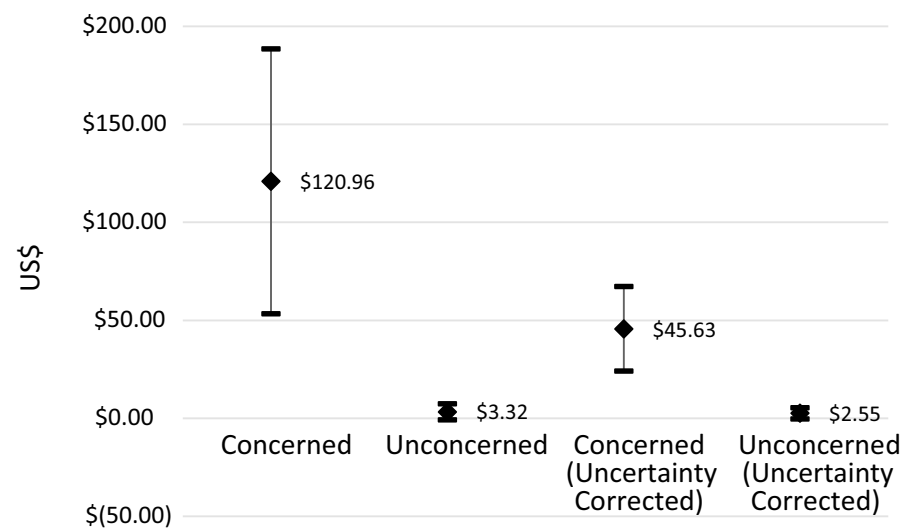

Fig. 3 Willingness-to-Give Estimates Using Population Means by Concern Levels. Note: These estimates are based on Model 4. WTG estimates were corrected for uncertainty by recoding positive responses whose certainty levels were below 7 on a 1-10 scale as negative

subsidized immunization programs for all. By calibrating our models to reflect US population characteristics, we predict that the median individual would be willing to give approximately $\$ 26$ to fund immunization programs for the indigent or uninsured. Our estimates are comparable to the Americans' monthly median donation of \$29 for secular organizations reported by Choi and DiNitto (2012). Conservative estimates indicate the median individual is willing to give about $\$ 13$. If we aggregate that estimate over 250 million adults (18 + years of age) living in the United States (US Census Bureau, 2019), nongovernmental organizations would have the potential to raise at least $\$ 3.25$ billion dollars to fund immunization campaigns.

We found that the willingness to give is directly related to income, education, selfreported concern regarding the pandemic, and recent influenza vaccination; and inversely associated with age and household size, largely consistent with the prior findings on WTG (see reviews by Wiepking \& Bekkers, 2012; Bekkers \& Wiepking, 2011; Matloch, 2018). We also found ethnic- and gender-based disparities in the willingness to give for nongovernmental immunization programs. Women would give about half of what men would donate. Einolf (2011) found similar gender disparities in the amount donated to religious charities (men: $\$ 100$ vs women: $\$ 65$ ).

The influence of concern on WTG deserves further attention. WTG predictions by level of concern indicate that people who are not concerned with COVID-19 would not contribute to immunization programs for others. In contrast, individuals who are 'concerned' or 'very concerned' will give about $\$ 120$, or at least $\$ 45$ after correcting for donors' uncertainty about their future giving (see Fig. 3). Although our study does not look into temporal stability of WTG estimates, our results suggest that NGOs would receive more funding in times of high concern, for instance in the early stages of a pandemic. Once people learn how to deal with the threat of the virus, or policy and technological solutions are deployed, donors may be less likely to support immunization programs. Therefore, solicitations for charitable giving at the beginning or peak of a pandemic may be most successful as measured by the number and magnitude of donations.

Our findings also suggest that altruism is the predominant reason to give in the context of immunization against a pandemic, reported by a majority of respondents who 
would donate to nongovernmental immunization campaigns. This is consistent with recent studies that found that prosocial attitudes are related to WTG amid the COVID19 pandemic (Abel et al., 2021; Campos-Mercade et al., 2021). Impure altruism in the form of benefiting from a public good was the second most popular motive, as reported by almost $29 \%$ of those who would give. Most of those impurely-altruistic individuals considered to give in order to restore the economy, and fewer did so to avoid being infected by others. This suggests that, among this group, the economic fallout was more relevant than the public health crisis. 'Warm-glow' motives were less prevalent among our respondents, reported by less than $12 \%$ of those who would give.

Our analysis of motivations to give can yield insights into how nongovernmental organizations may appeal to potential donors. For instance, targeting campaigns towards females, nongovernmental organizations would want to appeal to their altruistic nature, of serving the social good by making sure that all people have the means to avoid being infected. In contrast, when appealing to higher income donors, they may emphasize the protective role of the immunization campaigns to support economic stability by stifling the spread of the virus. Similarly, as seasonal flu vaccinations are administered, NGOs could target recipients to ask for donations-appealing to their concerns to protect their own health and loss of productivity due to the pandemic.

In this study, we focused on nongovernmental immunization programs that can be crucial to eradicate future pandemics in the United States, evaluating, for the first time, willingness and motives to give to vaccination campaigns specifically. Yet, as any other study, our analysis has some limitations. In retrospect, we could have elicited intentions to get vaccinated if the vaccine was approved under an emergency protocol to test whether nongovernmental immunization programs are considered substitutes or complements of getting vaccinated. Moreover, we could have investigated whether that relationship was moderated by expectations regarding the impending vaccine's effectiveness. That analysis would shed further light on the motives for giving because individuals who expect to be well-protected are likely to give to nongovernmental immunization programs due to altruistic motives. Vaccinated donors should not derive any additional direct benefit from the public good of herd immunity. However, to the extent that herd immunity influences government policies on social distancing and economic opportunity, it could still represent an impurely altruistic motive. Conversely, donors who do not expect the vaccine to be effective, or who do not intend to get vaccinated, are likely to give to reduce their own risk of being infected. We leave the investigation of these effects for future studies.

Funding This research was supported by funding from Fairfield University.

\section{Declarations}

Conflict of interest The authors have no conflicts of interest to declare that are relevant to the content of this article.

Ethics approval The questionnaire and methodology of this study was granted approval by Fairfield University Institutional Review Board under protocol no. 3758-2020 and Sacred Heart University's Institutional Review Board under Protocol No. 200416A.

Consent to participate Informed consent was obtained from all individual participants included in the study. 


\section{References}

Abel, M., Byker, T., \& Carpenter, J. (2021). Socially optimal mistakes? Debiasing COVID-19 mortality risk perceptions and prosocial behavior. Journal of Economic Behavior and Organization, 183, 456-480.

Almario, C. V., May, F. P., Maxwell, A. E., Ren, W., Ponce, N. A., \& Spiegel, B. M. (2016). Persistent racial and ethnic disparities in flu vaccination coverage: Results from a population-based study. American Journal of Infection Control, 44(9), 1004-1009.

Andreoni, J. (1989). Giving with impure altruism: Applications to charity and Ricardian equivalence. Journal of Political Economy, 97(6), 1447-1458.

Andreoni, J. (1990). Impure altruism and donations to public goods: A theory of warm-glow giving. Economic Journal, 100(401), 464-477.

Andreoni, J., Brown, E., \& Rischall, I. (2003). Charitable giving by married couples who decides and why does it matter? Journal of Human Resources, 38(1), 111-133.

Araña, J. E., \& León, C. J. (2002). Willingness to pay for health risk reduction in the context of altruism. Health Economics, 11(7), 623-635.

Becker, G. S. (1974). A theory of social interactions. Journal of Political Economy, 82(6), 1063-1093.

Bekkers, R., \& Wiepking, P. (2011). Who gives? A literature review of predictors of charitable giving part one: Religion, education, age and socialisation. Voluntary Sector Review, 2(3), 337-365.

Blumenschein, K., Blomquist, G., Johannesson, M., Horn, N., \& Freeman, P. (2008). Eliciting willingness to pay without bias: Evidence from a field experiment. Economic Journal, 118, 114-137.

Boyle, K. J. (2017). Contingent valuation in practice. In P. A. Champ, K. J. Boyle, \& T. C. Brown (Eds.), A primer on nonmarket valuation. Berlin: Springer.

Brañas-Garza, P., Jorrat, D., Alfonso-Costillo, A., Espín, A.M., Garcia, T., \& Kovář́k, J. (2020). Exposure to the COVID-19 pandemic and generosity. MPRA Paper No. 103389.

Brown, A. L., Meer, J., \& Williams, J. F. (2019). Why do people volunteer? An experimental analysis of preferences for time donations. Management Science, 65(4), 1455-1468.

Campos-Mercade, P., Meier, A. N., Schneider, F. H., \& Wengström, E. (2021). Prosociality predicts health behaviors during the COVID-19 pandemic. Journal of Public Economics, 195, 104367.

Champ, P. A., Moore, R., \& Bishop, R. C. (2009). A comparison of approaches to mitigate hypothetical bias. Agricultural and Resource Economics Review, 38(2), 166-180.

Choi, N. G., \& DiNitto, D. M. (2012). Predictors of time volunteering, religious giving, and secular giving: Implications for nonprofit organizations. Journal of Sociology \& Social Welfare, 39(2), 93-120.

Crumpler, H., \& Grossman, P. J. (2008). An experimental test of warm glow giving. Journal of Public Economics, 92(5-6), 1011-1021.

Eckel, C., Grossman, P. J., \& Milano, A. (2007). Is more information always better? An experimental study of charitable giving and Hurricane Katrina. Southern Economic Journal, 74(2), 388-411.

Einolf, C. J. (2011). Gender disparities in the correlates of volunteering and charitable giving. Nonprofit and Voluntary Sector Quarterly, 40(6), 1092-1112.

García, L. Y., \& Cerda, A. A. (2020). Contingent assessment of the COVID-19 vaccine. Vaccine, 38(34), 5424-5429.

Greene, W. H. (2018). Econometric analysis (8th ed.). London: Pearson.

Haab, T., Lewis, L., \& Whitehead, J. (2020). State of the art of contingent valuation. In Oxford Research Encyclopedia of Environmental Science.

Harrison, G. W., \& Lesley, J. C. (1996). Must contingent valuation surveys cost so much? Journal of Environmental Economics and Management, 31, 79-95.

Hershey, J. C., Asch, D. A., Thumasathit, T., Meszaros, J., \& Waters, V. V. (1994). The roles of altruism, free riding, and bandwagoning in vaccination decisions. Organizational Behavior and Human Decision Processes, 59(2), 177-187.

Holmes, T. P., Bergstrom, J. C., Huszar, E., Kask, S. B., \& Fritz, O., III. (2004). Contingent valuation, net marginal benefits, and the scale of riparian ecosystem restoration. Ecological Economics, 49, 19-30.

Johnston, R. J., Boyle, K. J., Adamowicz, W., Bennett, J., Brouwer, R., Cameron, T. A., Hanemann, W. M., Hanley, N., Ryan, M., Scarpa, R., Tourangeau, R., \& Vossler, C. A. (2017). Contemporary guidance for stated preference studies. Journal of the Association of Environmental and Resource Economists, 4(2), 319-405.

Kim, S. Y., Sagiraju, H. K., Russell, L. B., \& Sinha, A. (2014). Willingness-to-pay for vaccines in low-and middle-income countries: A systematic review. Annals of Vaccines and Immunization, 1(1), 1001.

Kolenikov, S. (2014). Calibrating survey data using iterative proportional fitting (raking). STATA Journal, 14(1), 22-59.

Liljas, B., \& Blumenschein, K. (2000). On hypothetical bias and calibration in cost-benefit studies. Health Policy, 52, 53-70. 
Liu, J. T., Hammitt, J. K., Wang, J. D., \& Tsou, M. W. (2005). Valuation of the risk of SARS in Taiwan. Health Economics, 14(1), 83-91.

Long, M. C., \& Krause, E. (2017). Altruism by age and social proximity. PLoS ONE, 12(8), e0180411.

Lu, P., O'Halloran, A., Williams, W. W., Lindley, M. C., Farrall, S., \& Bridges, C. B. (2015). Racial and ethnic disparities in vaccination coverage among adult populations. American Journal of Preventive Medicine, 49(6 Suppl 4), S412-S425.

Marin, M. G., Johanson, W. G., \& Salas-Lopez, D. (2002). Influenza vaccination among minority populations in the United States. Preventive Medicine, 34(2), 235-241.

Matloch, J. (2018). The assessment of German cultural landscapes. Springer VS, Wiesbaden. https://doi. org/10.1007/978-3-658-21416-6

Mesch, D. J., Rooney, P., Steinberg, K., \& Denton, B. (2006). The effects of race, gender, and marital status on giving and volunteering in Indiana. Nonprofit and Voluntary Sector Quarterly, 35(4), 565-587.

Mozumder, P., Vásquez, W., \& Marathe, A. (2011). Consumers' preferences for renewable energy in the southwest USA. Energy Economics, 33, 1119-1126.

Quinn, S. C., Jamison, A., Freimuth, V. S., An, J., Hancock, G. R., \& Musa, D. (2017). Exploring racial influences on flu vaccine attitudes and behavior: Results of a national survey of White and African American adults. Vaccine, 35(8), 1167-1174.

Ruggles, S., Flood, S., Goeken, R., Grover, J., Meyer, E., Pacas, J., \& Sobek, M. (2020). IPUMS USA: Version 10.0 . Minneapolis, MN: IPUMS. https://doi.org/10.18128/D010.V10.0

Ryan, M., Mentzakis, E., Jareinpituk, S., \& Cairns, J. (2017). External validity of contingent valuation: Comparing hypothetical and actual payments. Health Economics, 26(11), 1467-1473.

Shim, E., Chapman, G. B., Townsend, J. P., \& Galvani, A. P. (2012). The influence of altruism on influenza vaccination decisions. Journal of the Royal Society Interface, 9(74), 2234-2243.

Smith, P. J., Chu, S. Y., \& Barker, L. E. (2004). Children who have received no vaccines: Who are they and where do they live? Pediatrics, 114(1), 187-195.

Tonin, M., \& Vlassopoulos, M. (2010). Disentangling the sources of pro-socially motivated effort: A field experiment. Journal of Public Economics, 94(11-12), 1086-1092.

U.S. Census Bureau. (2019). Current Population Survey, Annual Social and Economic Supplement

Vásquez, W. F., Mozumder, P., Hernández, J., \& Berrens, R. (2009). Willingness to pay for safe drinking water: Evidence from Parral Mexico. Journal of Environmental Management, 90(11), 3391-3400.

Wiepking, P., \& Bekkers, R. (2012). Who gives? A literature review of predictors of charitable giving. Part Two: Gender, family composition and income. Voluntary Sector Review, 3(2), 217-245.

Publisher's Note Springer Nature remains neutral with regard to jurisdictional claims in published maps and institutional affiliations. 